\title{
Prevalence of Hashimoto's thyroiditis in psoriasis patients
}

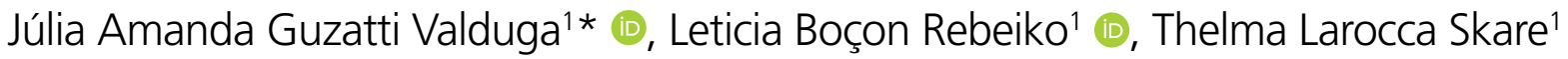

\begin{abstract}
SUMMARY
OBJECTIVE: To study the prevalence of Hashimoto's Thyroiditis in a sample of psoriasis patients.

METHODS: Cross-sectional observational study of 120 individuals ( 60 with psoriasis and 60 control subjects) paired by gender and age for thyroid function (thyroid stimulating hormone, free T4), antithyroperoxidase and antithyroglobulin tests and physical examination. Psoriasis Area and Severity Index and Nail Psoriasis Severity Index were evaluated simultaneously. Epidemiological, clinical and treatment data was collected from medical records. Patients with documented hypothyroidism and/or goiter associated with positive antithyroperoxidase antibody were considered to have Hashimoto's Thyroiditis.

RESULTS: The prevalence of Hashimoto's Thyroiditis in the group with psoriasis was 21.6\%; in the control group, it was 4/60 (6.6\%) with $p=0.03(\mathrm{OR}=3.8 ; 95 \% \mathrm{Cl} 1.18-12.6)$. In the group of patients with psoriasis, Hashimoto's Thyroiditis was more common in women $(p=0.002)$ and less common in those who had polyarticular arthropathic psoriasis $(p=0.05)$ and plaque psoriasis $(p=0.005)$. A logistic regression showed that the only independent variable associated with Hashimoto's thyroiditis was plaque psoriasis.

CONCLUSIONS: There is a high prevalence of Hashimoto's Thyroiditis in psoriatic patients, especially in women. Hashimoto's Thyroiditis is less common in patients with the plaque form of psoriasis.

KEYWORDS: Psoriasis. Hashimoto disease. Thyroiditis.
\end{abstract}

\section{INTRODUCTION}

Psoriasis is a common autoimmune disease, clinically expressed by scaly and red plaques and papules induced by premature keratinocyte maturation ${ }^{1}$. A genetic predisposition and environmental factors are involved on its pathogenesis ${ }^{1}$.

Patients with psoriasis may suffer from other autoimmune diseases, such as vitiligo, bullous pemphigoid, systemic lupus, rheumatoid arthritis and Chron's disease ${ }^{2}$. Hashimoto's Thyroiditis (HT) has also been described as more common in psoriasis than in the general population, although current studies are controversial ${ }^{1-4}$. Some authors have found that psoriasis is more common in HT patients, and that its severity is influenced by thyroid hormone levels ${ }^{5,6}$. In the skin, thyroid's hormone generates the production of epidermal growth factor, which responds for proliferation and differentiation of keratinocytes ${ }^{7}$. A common signaling pathway in psoriasis and HT has been observed with increased levels of Interferon Gamma (INF-Y), Interleukin (IL)-23 and Th17 cells, which explains the association of these two diseases ${ }^{7,8}$.

Both HT and psoriasis are diseases influenced by genetic background. Therefore, the association of these two diseases may differ according to the studied population. In the present study, an association between psoriasis and HT in a sample of Brazilian patients was sought, as well as a possible association of this combination with the clinical profile of psoriasis.

\section{METHODS}

The local committee of Ethics in Research approved the present project and all participants signed consent. We

\footnotetext{
${ }^{1}$ Hospital Evangélico Mackenzie - Curitiba (PR), Brasil.

*Corresponding author: jagv7965@outlook.com

Conflicts of interest: the authors declare there is no conflicts of interest. Funding: none.

Received on August 18, 2020. Accepted on September 20, 2020.
} 
included 120 individuals (60 with psoriasis and 60 control subjects) of both genres and with at least 18 years of age. This is a cross-sectional study with a convenience sample that includes all patients with psoriasis from a single tertiary care center that came for regular consultations over the period of one year and agreed to participate in the study. Pregnant women were excluded. Epidemiological data (gender, age, disease duration, tobacco exposure), data on psoriasis (type of psoriasis, presence and type of ungueal involvement, presence and form of arthritis and treatment data) were obtained through chart review. Psoriasis extension was measured by Psoriasis Area and Severity Index (PASI) ${ }^{9}$, and ungueal involvement was measured by Nail Psoriasis Severity Index (NAPSI $)^{10}$. Serum to determine the thyroid stimulating hormone (TSH), free thyroxine (T4) and antithyroid antibodies were collected. TSH and T4 were measured by chemiluminescence; regular TSH values varied between $0.3-4.0 \mathrm{mUI} /$ $\mathrm{mL}$ and $\mathrm{T} 4$ between $0.7-1.8 \mathrm{ng} / \mathrm{dL}$. Serum antibodies to $\mathrm{Tg}$ (antithyroglobulin antibodies) and TPO Ab (antithyroperoxidase antibodies) were determined by immunometric assays (Inova-KIT, Quanta Lite Inova Diagnostics, San Diego, CA, USA). Test results were considered positive if the levels were $\geq 50 \mathrm{IU} / \mathrm{mL}$ for TPO Ab and $\geq 325 \mathrm{IU} / \mathrm{mL}$ for Tg Ab. HT was diagnosed either when hypothyroidism (high TSH and low T4) was detected, or when the need for thyroid hormone replacement therapy or goiter were associated with positive TPO Ab with or without $\mathrm{Tg} A \mathrm{~b}^{11}$.

The group used as control was obtained from a gynecology clinic (women who went for a regular checkup) and from an ophthalmology clinic (patients who went for refraction), paired by age and gender, and proceeded from the same geographical area (same iodine intake) as patients with psoriasis.

Data was gathered in contingency and frequency tables. The test of Shapiro Wilk was used to analyze data distribution. To compare nominal data, $\chi^{2}$ and Fisher tests were used. To compare nominal data, Mann Whitney and unpaired t-test were calculated. A logistic regression was done using the presence of HT as the dependable variable and including all independent variables that associated with $\mathrm{HT}$ with $\mathrm{p}<0.1$ to test their independence. The significance adopted was of $5 \%$.

\section{RESULTS}

\section{Description of studied sample}

The description of the studied sample is on Table 1. In this sample, the prevalence of HT was $21.6 \%(13 / 60)$.

In the control sample, 40/60 (66.6\%) were females (pairing with psoriasis sample with $\mathrm{p}=1.0$ ) and the average age was
54.5 years old (IQR=40.2 to 62.0) with pairing by age with $\mathrm{p}=0.55$. In this group, $4 / 60(6.6 \%)$ had HT.

When the prevalence of HT in psoriasis group (21.6\%) was compared with control subjects (6.6\%), an odds ratio of 3.8 (95\%CI 1.18-12.6; $\mathrm{p}=0.03)$ was found.

\section{Comparison of the characteristics of psoriasis in patients with and without HT}

The comparison of psoriasis sample with and without HT is on Table 2.

Figure 1 shows the comparison of psoriasis skin subtypes.

A logistic regression including variables with $\mathrm{p}<0.1$ (gender, plaque psoriasis, guttate psoriasis and polyarticular form of arthritis) showed that only plaque psoriasis was an independent variable associated with HT (OR=0.14; 95\%CI 0.03-0.58).

\section{DISCUSSION}

Our results showed a high prevalence of HT among psoriasis patients of our region. This finding corroborates those of previous works by Alidrisi et al. ${ }^{7}$ and Wang et al. ${ }^{12}$. Also, a work by Khan et al. ${ }^{13}$, which looked for psoriasis in 8,214 patients with thyroid disease, found a higher prevalence of this skin disease in those with anti-TPO antibodies.

Gul et al. ${ }^{14}$ could not prove the association of psoriasis with HT in their 105 patients with psoriasis, but these authors excluded patients with associated psoriatic arthritis from their studies. This could explain the dissimilarity of the results. Curiously, a study in individuals with psoriatic arthritis found a higher prevalence of HT in those with the polyarticular form of this disease ${ }^{15}$. Our different results may be explained by the fact that we studied patients with psoriasis in general, and not only plaque psoriasis. Other explanation for this difference could be the ethnicity of the studied samples. The Brazilian population is highly mixed, and this provides a unique genetic background. It is also worthwhile to note that the polyarticular involvement did not associate independently with HT, but the plaque psoriasis did. Both variables, plaque psoriasis and polyarticular form, were less common in HT patients. So, it is possible that the true association behind this finding involves plaque psoriasis, and not the arthritis form.

The existence of more than one autoimmune disease in the same patient is a well-known event in the literature $^{16}$. A shared genetic predisposition or exposition to a common environmental precipitating factor are some of the explanations given ${ }^{16,17}$. The occurrence of psoriasis and HT in monozygotic twins favors the role of genetic contribution $^{3}$. Also, the genetic polymorphisms of the cytotoxic 
Table 1. Main characteristics of psoriasis sample $(n=60)$

\begin{tabular}{|c|c|c|}
\hline Females $(n \%)$ & $40 / 60$ & 66.6 \\
\hline Auto declared caucasian background ( $n \%)$ & $52 / 60$ & 86.6 \\
\hline Tobacco exposure (current and ex-smokers) ( $\mathrm{n} \%)$ & $19 / 60$ & 31.6 \\
\hline Mean age (years) (standard deviation) & $21.0-81.0$ & $51.4 \pm 15.5$ \\
\hline Average body mass index $\left(\mathrm{kg} / \mathrm{m}^{2}\right)$ (interquartile range) & $17.61-45.40$ & $26.98(24.25-31.97)$ \\
\hline Average disease duration (years) (interquartile range) & $1-35.0$ & $10.0(5.23-18.5)$ \\
\hline \multicolumn{3}{|l|}{ Associated diseases } \\
\hline Arterial hypertension ( $\mathrm{n} \%)$ & $26 / 60$ & 43.3 \\
\hline Diabetes mellitus ( $\mathrm{n} \%$ ) & $17 / 60$ & 28.3 \\
\hline Depression ( $n \%)$ & $7 / 60$ & 11.6 \\
\hline Vitiligo (n\%) & $1 / 60$ & 1.6 \\
\hline \multicolumn{3}{|l|}{ Psoriasis skin characteristics } \\
\hline Plaque psoriasis (n\%) & $43 / 60$ & 71.6 \\
\hline Palmo-plantar psoriasis ( $\mathrm{n} \%)$ & $7 / 60$ & 11.6 \\
\hline Guttata (n\%) & $5 / 60$ & 8.3 \\
\hline Inverted psoriasis & $3 / 60$ & 5.0 \\
\hline Erythrodermic (n\%) & $1 / 60$ & 1.6 \\
\hline Scalp involvement (n\%) & $26 / 60$ & 43.3 \\
\hline Average psoriasis area and severity index (interquartile range) & $0-29.5$ & $2.10(0.82-3.88)$ \\
\hline \multicolumn{3}{|l|}{ Psoriasis nail characteristics } \\
\hline Total of patients with nail involvement ( $n \%)$ & $36 / 60$ & 60 \\
\hline Onycholysis (n\%) & $14 / 60$ & 23.3 \\
\hline Pitting (n\%) & $18 / 60$ & 30 \\
\hline Hemorrages ( $\mathrm{n} \%)$ & $4 / 60$ & 6.6 \\
\hline Leukoniquia (n\%) & $4 / 60$ & 6.6 \\
\hline Oilstain (n\%) & $2 / 60$ & 3.3 \\
\hline Crumbling ( $\mathrm{n} \%)$ & $3 / 60$ & 5 \\
\hline Average nail psoriasis severity index (interquartile range) & $0-20.0$ & $1.50(0-4.0)$ \\
\hline \multicolumn{3}{|l|}{ Psoriatic articular involvement } \\
\hline Polyarticularform (n\%) & $12 / 60$ & 20 \\
\hline Oligoarticularform (n\%) & $7 / 60$ & 11.6 \\
\hline Spondyloarthritis (n\%) & $4 / 60$ & 6.6 \\
\hline \multicolumn{3}{|l|}{ Treatment } \\
\hline Phototherapy (n\%) & $8 / 60$ & 13.3 \\
\hline Only topical treatment $(\mathrm{n} \%)$ & $26 / 60$ & 43.3 \\
\hline Acitretin (n\%) & $2 / 60$ & 3.3 \\
\hline Methotrexate (n\%) & $23 / 60$ & 38.2 \\
\hline Cyclosporin (n\%) & $3 / 60$ & 5 \\
\hline Leflunomida (n\%) & $4 / 60$ & 6.6 \\
\hline Adalimumab (n\%) & $4 / 60$ & 6.6 \\
\hline Ustequinumab (n\%) & $4 / 60$ & 6.6 \\
\hline Etanercept (n\%) & $1 / 60$ & 1.6 \\
\hline
\end{tabular}


Table 2. Comparison of patients with psoriasis with and without Hashimoto's Thyroiditis

\begin{tabular}{|c|c|c|c|}
\hline & $\begin{array}{c}\text { With HT } \\
n=13\end{array}$ & $\begin{array}{l}\text { Without HT } \\
\qquad n=47\end{array}$ & $p$ \\
\hline Females ( $\mathrm{n} \%)$ & $13 / 13-100$ & $27 / 47(57.4)$ & 0.002 \\
\hline Caucasian ethnic background (autodeclared) & $13 / 13-100$ & $39 / 47(82.9)$ & 0.18 \\
\hline Tobbaco exposure (n\%) & $2 / 13-15.3$ & $17 / 47(36.1)$ & 0.19 \\
\hline Mean age (years) ( \pm standard deviation) & $51.2 \pm 19.7$ & $51.5 \pm 14.4$ & 0.95 \\
\hline Average disease duration (years) (interquartile range) & $7.0(1.0-18.5)$ & $11.0(6.0-19.0)$ & 0.36 \\
\hline Scalp involvement (\%) & $4 / 13-30.7$ & $22 / 47-46.8$ & 0.35 \\
\hline Median psoriasis area and severity index (interquartile range) & $1.4(0-3.45)$ & $2.7(1.0-6.3)$ & 0.10 \\
\hline Average nail psoriasis severity index (interquartile range) & $1(0-4.0)$ & $2.0(0-5.0)$ & 0.66 \\
\hline Polyarticulararthritis (\%) & $0 / 13$ & $12 / 47-25.5$ & 0.05 \\
\hline Oligoarticulararthritis (\%) & $1 / 13-7.6$ & $6 / 47-12.7$ & 1.000 \\
\hline Spondyloarthritis (\%) & 2/13-15.3 & $2 / 47-4.2$ & 0.20 \\
\hline
\end{tabular}

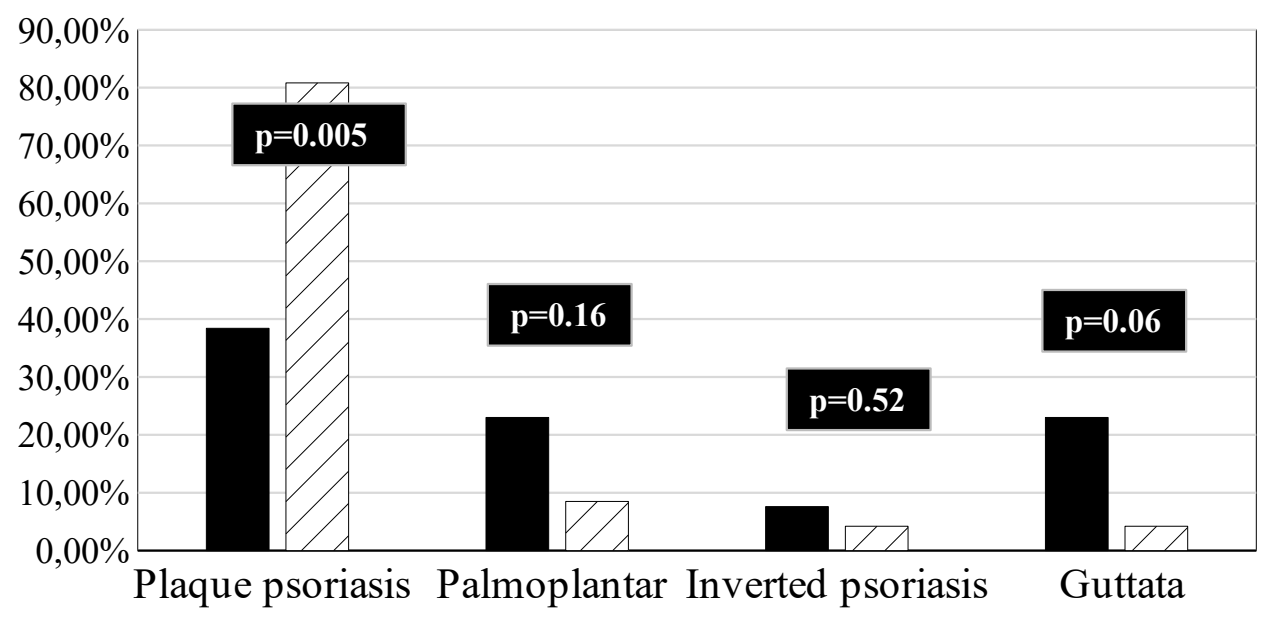

With Hashimoto $\square$ Without Hashimoto

Figure 1. Comparison of psoriasis skin subtypes in patients with and without Hashimoto thyroiditis. Patients with erythrodermic form not studied due to low number of cases.

T-lymphocyte regulatory gene (CTLA4), which plays an important role in the antigen presentation to $\mathrm{T}$ cells, has been connected to HT and psoriasis ${ }^{18}$. Concerning environmental pollution, smoking has been related to both psoriasis ${ }^{19}$ and $\mathrm{HT}^{20}$.
We also found that HT was less common in plaque psoriasis and this was an independent association. We have no good explanation for this finding. Al-Shobaili et al. ${ }^{21}$ have found that, in patients with plaque psoriasis, thyroid tissue modified by oxidative radicals, generated by the inflammatory process, 
may lead to new antigen formation, which induce autoantibodies. However, the exact meaning of this finding in the present context is unknown.

Recognizing the coexistence of these diseases is important in daily practice for at least two reasons. First, psoriasis patients are known to be obese, to have more metabolic syndromes and risk for cardiovascular diseases than the population in general ${ }^{22}$. Individuals with hypothyroidism, even subclinical, may develop dyslipidemia with high LDL and low HDL, favoring atherosclerosis $^{23}$. Therefore, hypothyroidism, if not recognized and left untreated, may further aggravate the metabolic consequences of psoriasis. The second reason is the well-known association of HT and thyroid malignancy ${ }^{24}$. The recognition of HT by the dermatologist who treats psoriasis will offer an opportunity for this professional to practice vigilance in this aspect.

\section{CONCLUSIONS}

A high prevalence of $\mathrm{HT}$ in our psoriasis sample was found. This combination was more common in females and occurred less frequently in those with plaque psoriasis and polyarticular arthritis.

\section{AUTHORS" CONTRIBUTIONS}

JAGV: Data Curation, Formal Analysis, Investigation, Resources, Software, Validation, Writing - Original Draft. LBR: Data Curation, Formal Analysis, Investigation, Resources, Software, Validation, Writing - Original Draft. TLS: Conceptualization, Methodology, Project Administration, Supervision, Validation, Writing - Review \& Editing.

\section{REFERENCES}

1. Ruffilli I, Ragusa F, Benvenga S, Vita R, Antonelli A, Fallahi P, et al. Psoriasis, psoriatic arthritis, and thyroid autoimmunity. Front Endocrinol (Lausanne). 2017;8:139. https://doi.org/10.3389/ fendo.2017.00139

2. Furue K, Ito T, Tsuji G, Kadono T, Nakahara T, Furue M. Autoimmunity and autoimmune co-morbidities in psoriasis. Immunology. 2018;154(1):21-7. https://doi.org/10.1111/imm. 12891

3. Kiguradze T, Bruins FM, Guido N, Bhattacharya T, Rademaker A, Florek AG, et al. Evidence for the association of Hashimoto's thyroiditis with psoriasis: a cross-sectional retrospective study. Int J Dermatol. 2017;56(5):553-6. https://doi.org/10.1111/ijd.13459

4. Vassilatou E, Papadavid E, Papastamatakis P, Alexakos D, Koumaki D, Katsimbri $P$, et al. No association of psoriasis with autoimmune thyroiditis. J Eur Acad Dermatol Venereol. 2017;31(1):102-6. https://doi.org/10.1111/jdv.13767

5. Robati RM, Toossi P, Rahmati-Roodsari M, Khalilazar S, Abolhasani E, Namazi N, et al. Association of psoriasis severity with serum prolactin, thyroid hormones, and cortisol before and after treatment. ScientificWorldJ.2013;2013:921819. https://doi.org/10.1155/2013/921819

6. Ribeiro RC, Apriletti JW, West BL,Wagner RL, Fletterick RJ, Schaufele $F$, et al. The molecular biology of thyroid hormone action. Ann N Y Acad Sci. 1995;758:366-89. https://doi. org/10.1111/j.1749-6632.1995.tb24843.x

7. Alidrisi HA, Al Hamdi K, Mansour AA. Is there any association between psoriasis and Hashimoto's thyroiditis? Cureus. 2019;11(3):e4269. https://doi.org/10.7759/cureus.4269

8. Bossowski A, Moniuszko M, Idźkowska E, Dąbrowska M, Jeznach M, Sawicka B, et al. Evaluation of CD4+CD161+CD196+ and CD4+IL-17+ Th17 cells in the peripheral blood of young patients with Hashimoto's thyroiditis and Graves' disease. Pediatr Endocrinol Diabetes Metab. 2012;18(3):89-95. PMID:23146786
9. Oji V, Luger TA. The skin in psoriasis: assessment and challenges. Clin Exp Rheumatol. 2015;33(5 Suppl 93):S14-9. PMID:26472560

10. Mukai MM, Poffo IF, Werner B, Brenner FM, Lima Filho JH. NAPSI utilization as an evaluation method of nail psoriasis in patients using acitretin. An Bras Dermatol. 2012;87(2):25662. https://doi.org/10.1590/S0365-05962012000200010

11. Caturegli $P$, De Remigis $A$, Rose NR. Hashimoto thyroiditis: clinical and diagnostic criteria. Autoimmun Rev. 2014;13(45):391-7. https://doi.org/10.1016/j.autrev.2014.01.007

12. Wang SH, Wang J, Lin YS, Tung TH, Chi CC. Increased risk for incident thyroid diseases in people with psoriatic disease: a cohort study. J Am Acad Dermatol. 2019;80(4):1006-12. https://doi.org/10.1016/j.jaad.2018.11.049

13. Khan SR, Bano A, Wakkee M, Korevaar TIM, Franco OH, Nijsten TEC, et al. The association of autoimmune thyroid disease (AITD) with psoriatic disease: a prospective cohort study, systematic review and meta-analysis. Eur J Endocrinol. 2017;177(4):347-59. https://doi.org/10.1530/EJE-17-0397

14. Gul U, Gonul M, Kaya I, Aslan E. Autoimmune thyroid disorders in patients with psoriasis. Eur J Dermatol. 2009;19(3):221-3. https://doi.org/10.1684/ejd.2009.0632

15. Antonelli A, Delle Sedie A, Fallahi P, Ferrari SM, Maccheroni M, Ferrannini $E$, et al. High prevalence of thyroid autoimmunity and hypothyroidism in patients with psoriatic arthritis. J Rheumatol. 2006;33(10):2026-8. PMID:17014017

16. Hemminki K, Li X, Sundquist K, Sundquist J. Familial association of inflammatory bowel diseases with other autoimmune and related diseases. Am J Gastroenterol. 2010;105(1):139-47. https://doi.org/10.1038/ajg.2009.496

17. Zhao CN, Xu Z, Wu GC, Mao YM, Liu LN, Qian-Wu, et al. Emerging role of air pollution in autoimmune diseases. Autoimmun Rev. 2019;18(6):607-14. https://doi.org/10.1016/j. autrev.2018.12.010 
18. Muto M, Deguchi H, Tanaka A, Inoue T, Ichimiya M. Association between T-lymphocyte regulatory gene CTLA4 single nucleotide polymorphism at position 49 in exon 1 and HLA-DRB $1 * 08$ in Japanese patients with psoriasis vulgaris. J Dermatol Sci. 2011;62(1):70-1. https://doi.org/10.1016/j.jdermsci.2010.10.012

19. Lønnberg AS, Skov L, Skytthe A, Kyvik KO, Pedersen OB, Thomsen SF. Smoking and risk for psoriasis: a populationbased twin study. Int J Dermatol. 2016;55(2):e72-8. https:// doi.org/10.1111/ijd.13073

20. Vestergaard P. Smoking and thyroid disorders: a meta-analysis. Eur J Endocrinol. 2002;146(2):153-61. https://doi.org/10.1530/ eje.0.1460153

21. Al-Shobaili HA, Ahmed AA, Rasheed Z. Recognition of oxidized albumin and thyroid antigens by psoriasis autoantibodies. A possible role of reactive-oxygen-species induced epitopes in chronic plaque psoriasis. Saudi Med J. 2015;36(12):1408-19. https://doi.org/10.15537/smj.2015.12.12612

22. Gisondi P, Fostini AC, Fossà I, Girolomoni G, TargherG. Psoriasis and the metabolic syndrome. Clin Dermatol. 2018;36(1):21-8. https://doi.org/10.1016/j.clindermatol.2017.09.005

23. RastgooyeHaghi A, Solhjoo M, Tavakoli MH. Correlation between subclinical hypothyroidism and dyslipidemia. Iran $J$ Pathol. 2017;12(2):106-11. PMID:29515631

24. Silva de Morais N, Stuart J, Guan H, Wang Z, Cibas ES, Frates $M C$, et al. The impact of Hashimoto thyroiditis on thyroid nodule cytology and risk of thyroid cancer. J Endocr Soc. 2019;3(4):791-800. https://doi.org/10.1210/ js.2018-00427 